This PDF is a selection from an out-of-print volume from the National Bureau of Economic Research

Volume Title: Themes in the Economics of Aging

Volume Author/Editor: David A. Wise, editor

Volume Publisher: University of Chicago Press

Volume ISBN: 0-226-90284-6

Volume URL: http://www.nber.org/books/wise01-1

Publication Date: January 2001

Chapter Title: Trends in Medicare Spending Near the End of Life

Chapter Author: Jeffrey Geppert, Mark B. McClellan

Chapter URL: http://www.nber.org/chapters/c10327

Chapter pages in book: (p. $201-216)$ 


\title{
Trends in Medicare Spending Near the End of Life
}

\author{
Jeffrey Geppert and Mark McClellan
}

Recent decades have witnessed dramatic improvements in health at older ages, including reductions in both mortality and morbidity. Although real growth in health care costs has accompanied improvements in health for the past fifty years, improvements in health give hope that avoided medical utilization due to better health may lower health care costs, or at least significantly reduce the rate of growth. In this paper, we determine the importance of changes in Medicare costs that resulted from declines in agespecific mortality between 1988 and 1995, and describe the impact of the mortality improvement on Medicare expenditure trends.

A number of experts have suggested that improvements in health may work to reduce significantly the burden of health care on the economy (see Vaupel 1997, Pardes 1999, and Singer and Manton 1998). Some improvements in health are likely to be the result of the innovations that avoid costly illnesses or reduce their cost of treatment (e.g., new medical therapies and pharmaceuticals that replace expensive surgical procedures). Medical innovations may also have an indirect impact by increasing labor productivity, reducing the relative magnitude of the health care cost burden. Other studies have documented improvements in health due to nonmedical factors such as better information, behavioral improvements, and economic developments that reduce disease morbidity (see Kennedy 1994). All else equal, all of these sources of improvements in health status

Jeffrey Geppert is a senior research analyst at the National Bureau of Economic Research. Mark McClellan is associate professor of economics and of medicine at Stanford University and a research associate of the National Bureau of Economic Research.

We thank Philip Ellis, Victor Fuchs, and Alan Garber for helpful discussions, and the National Institute on Aging for financial support. The opinions expressed in this paper do not represent the views of the U.S. Department of the Treasury. 
would be expected to reduce the intensity of health care use, leading to lower overall health care spending.

In this paper, we present quantitative evidence on the likely importance of improvements in health for reducing future health care costs, focusing on changes in mortality. Perhaps the most widely cited paper on medical spending near death is Lubitz and Riley (1993), which describes trends in the share of Medicare program payments spent on persons aged sixty-five and older in the last year of life from 1976 to 1988. The principal finding of Lubitz and Riley is the large share of Medicare expenditures in the last year of life - around 28 percent of total expenditures. A second finding is that Medicare expenditures at the end of life decline with age.

Supporters of the view that health improvements should reduce health care costs have emphasized these findings. If individuals are living longer over time, then the higher costs of death are deferred. In addition, because costs of dying are lower at older ages, death may be less costly when it eventually occurs. Against these sources of saving are, first, the fact that medical costs rise with age among survivors, and second, the fact that health care costs have generally risen over time. Also, Medicare spending might rise because of increased longevity, although the effect has been estimated as not very large (see Lubitz 1995).

Although Lubitz and Riley's (1993) results have not previously been applied to the problem of understanding the implications of improving health for Medicare spending growth, they are directly relevant to considering the likely impact of improving survival on spending. They found that the share of Medicare spending that occurred in the last year of life had changed little during their 1976-88 study period, despite the improvements in life expectancy. This constancy despite substantial mortality improvements suggests that other factors may have been more important in determining overall spending levels. For example, many studies have documented greater use of various intensive medical procedures on Medicare beneficiaries during this time period. Alternatively, the introduction or expansion of Medicare benefits, like home health and hospice, may have influenced utilization and costs for both survivors and decedents. In any case, the constancy of the share spent on decedents suggests that other factors dominated the "health effect."

We extend the Lubitz and Riley (1993) work on Medicare spending near the end of life from 1988 to 1995, to provide direct evidence on the expenditure consequences of improved survival in Medicare during a longer and more recent period. Our goal is to present empirical evidence from the past decade on the relative importance of changes in expenditures associated with improvements in mortality, compared to changes in expenditures given survival status, and to examine how that empirical evidence differs by gender and age. 


\subsection{Data and Methods}

As in the original Lubitz and Riley (1993) article, our data come from a longitudinal 5 percent random sample of Medicare beneficiaries. Rather than the Continuous Medicare History Sample, we calculate program payments from detailed micro-level Medicare claims data. The detailed claims permit us to explore the use and timing of specific services, and the diagnoses associated with them, in far more detail. Date of death was drawn from the Health Care Financing Administration (HCFA; 2000) Medicare Provider Analysis and Review File (MEDPAR), which in turn gets validated date-of-death information from Social Security records. Information on Medicare program payments and types of service come from MEDPAR and from HCFA's (2000) the Physician/Supplier Standard Analytic File (SAF), Home Health SAF and Hospice SAF, and Outpatient Hospital SAF.

Our sample includes only Medicare beneficiaries sixty-five years of age or older. Medicare beneficiaries enrolled in health maintenance organizations (HMO's) were excluded from the calculation of average program payments by type of service because some types of Medicare data are incomplete for HMO members. For other calculations, we included these HMO members, because monthly Medicare payments to their health plans are known. We report data from 1988, 1989, 1992, and 1995. The number of persons in each sample averaged 1.6 million beneficiaries.

As in Lubitz and Riley (1993), we assigned annual Medicare payments either to decedents (beneficiaries in the last year of life) or to survivors (all others). Because our data include dates of service for all service types, we assigned program payments to decedents or survivors on that basis (by date of discharge for inpatient and skilled nursing facility care). For example, a beneficiary who died in 1992 would contribute all 1992 program payments to decedent spending in 1992. A beneficiary who died on 1 April 1993 would contribute 1992 program payments incurred from 1 January 1992 to 30 March 1992 and 0.33 of a person-year to survivors, and program payments incurred after 1 April 1992 and 0.67 of a person-year to decedents. Beneficiaries who did not die in 1992 or 1993 contribute 100 percent of 1992 program payments and a full person-year to survivors.

To calculate the share of Medicare program payments to decedents, we divide the sum of program payments allocated to decedents using the method above by total Medicare payments (in constant dollars). We repeat the method by type of service, allocating acute inpatient, physician/supplier, hospital outpatient, and nonacute care (skilled nursing facility, home health agency, and hospice) to decedent and survivor spending to calculate the service share. Finally, we perform the allocation of dollars and personyears separately by age group. To calculate the average program payments 
for decedents (and survivors) by age group, we divide the sum of payments allocated to descendent (survivor) spending by the sum of decedent (survivor) person-year weights. The results reported in the tables are in constant dollars. To perform the decomposition described below, the age-specific average program payments for survivors and decedents are first inflated to 1995 dollars using the overall CPI.

We summarize the quantitative contribution of changes in mortality and changes in intensity to medical spending through a first-order decomposition of the total change in per capita expenditures over the 1988-95 period, $d(\exp )$ :

$$
\begin{aligned}
d(\exp )= & d\left[\Sigma_{j}(\text { share of population with health status type })_{j}\right. \\
& \left.*(\exp \mid \text { type })_{j}\right],
\end{aligned}
$$

where $j$ denotes a particular health status group. The decomposition is generally applicable; here, we focus on decedents and survivors within particular demographic cells $k$ :

$$
\begin{aligned}
d(\exp )= & d\left[\Sigma_{k} \operatorname{Pr}(\text { decedent })_{k} *(\exp \mid \text { decedent })_{k}\right. \\
& \left.+\operatorname{Pr}(\text { survivor })_{k} *(\exp \mid \text { survivor })_{k}\right] \\
= & \Sigma_{k}\left[d \operatorname{Pr}(\text { decedent })_{k} *(\exp \mid \text { decedent })_{k}\right. \\
& +d \operatorname{Pr}(\text { survivor })_{k} *(\exp \mid \text { survivor })_{k} \\
& +\operatorname{Pr}(\text { decedent })_{k} * d(\exp \mid \text { decedent })_{k} \\
& \left.+\operatorname{Pr}(\text { survivor })_{k} * d(\exp \mid \text { survivor })_{k}\right] \\
= & {[\text { mortality effect }+ \text { utilization effect }] }
\end{aligned}
$$

The first component of the change is the "mortality effect," or the change in per capita spending that results only from the change in the rate at which the elderly die at each age, holding program payments (and demographics) constant. The second component is the "utilization effect," or the change in per capita spending that results only from the change in program payments given survival status (i.e., decedent or survivor), holding mortality (and demographics) constant. This decomposition of per capita growth does not reflect the growth in total Medicare spending due to the increased number of elderly, which we label the "demographic effect." The demographic effect captures the consequences for program expenditures of changes in the number of elderly in each age and gender segment of the population.

The utilization effect is the result of changes in utilization of particular services, and also of changes in the prices of those services. Because Medi- 
care regulates service prices and has held price increases below the rate of inflation, growth in Medicare expenditures generally results from the provision of more or more-intensive covered services, and from changes in billing practices (e.g., upcoding).

\subsection{Results}

Figure 6.1 summarizes real expenditure growth rates by survival status, including a comparison to the earlier period studied by Lubitz and Riley (1993), and an even earlier period based on work by Piro and Lutins (1974). Over the past thirty years, the average annual percentage change in Medicare program payments has been high (3-7 percent per year) and relatively constant between survivors and decedents. In the earliest time period, between 1967 and 1976, real expenditure growth rates were slightly higher for decedents than survivors. In the time period between 1976 and 1988, real expenditure growth rates were the same for decedents and survivors and constant across ages. In more recent years, the growth rate for survivors has exceeded the growth rate for decedents, especially at older ages. The growth rate and pattern is largely the same for males and females from 1988 to 1995 , with the overall growth rate for males slightly less than for females. The acceleration in spending growth for survivors at older ages is slightly greater for females than for males.

Figure 6.2 summarizes real acute and nonacute spending growth rates

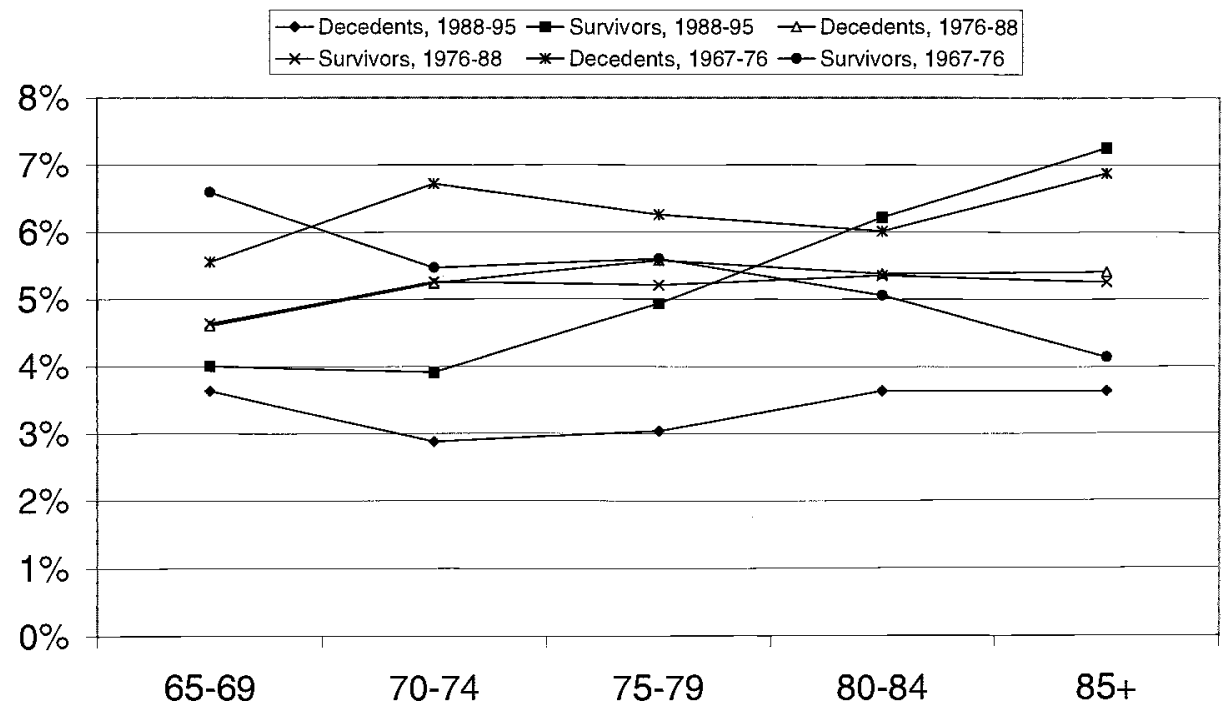

Fig. 6.1 Average annual percentage real change in Medicare payments per personyear, according to survival status and age, 1967-76, 1976-88, and 1988-95 
Acute: Decedents $\square-$ Acute: Survivors $\rightarrow-$ Nonacute: Decedents $\rightarrow$ Nonacute: Survivors

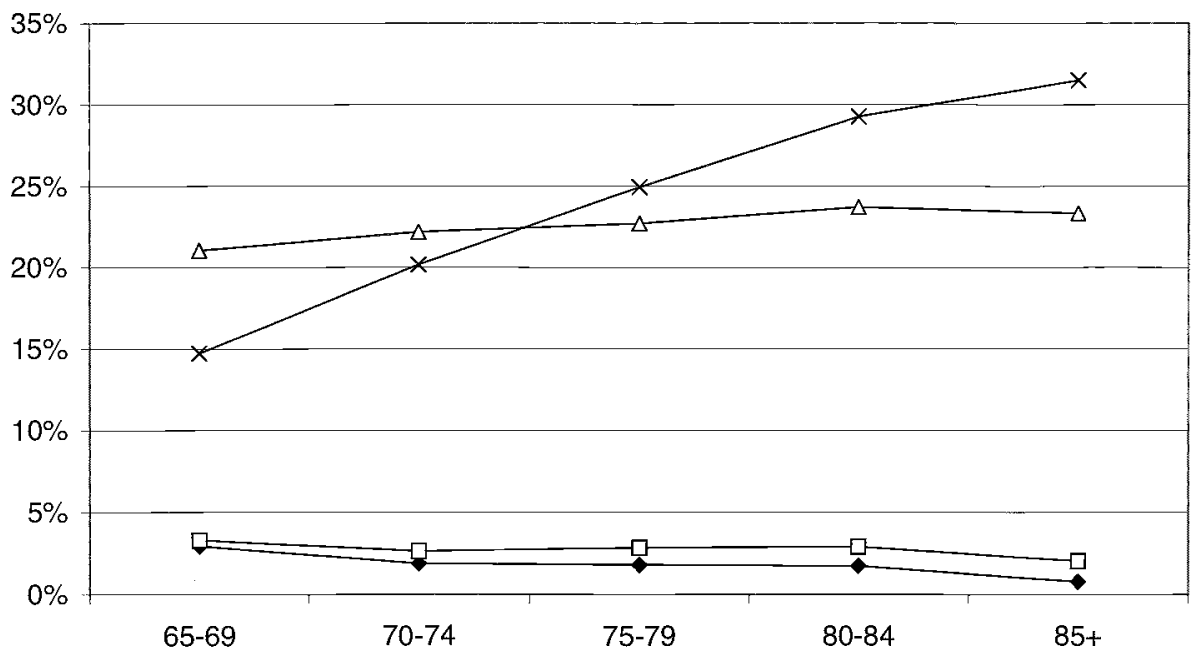

Fig. 6.2 Average annual percentage real change in Medicare payments per personyear, according to survival status and age, 1988-95

for the 1988-95 period. Nonacute care is defined to include skilled nursing facility (nonacute hospital) stays, home health care, and hospice care. These services are generally of lower intensity and are supportive in nature. Acute care includes services that are likely to be for acute illnesses, including acute hospitalizations, outpatient visits, and physician services. Many of these services are probably related to ongoing care or treatment for complications of chronic conditions. Nonetheless, in contrast to the nonacute services, these treatments consist primarily of medical interventions intended to alter the course of an illness, and not of supportive care. Such interventions are also provided in nonacute settings, but a much larger proportion of nonacute service use consists of supportive care for beneficiaries with chronic impairments. The figure shows that acute-care spending, which has historically been the bulk of Medicare expenditures, has increased at virtually identical rates for survivors and decedents, around 2-3 percent per year. Growth for nonacute services has been far more rapid since 1988, averaging well over 15 percent per year for both survivors and decedents. In contrast to a minimal relationship to age for decedents, the rate of nonacute spending growth for survivors was higher with increasing age, presumably reflecting the higher rates of chronic illness and disability among older survivors. As we describe in more detail below, nonacute spending growth has accounted for most of the spending growth in the past decade for decedents, and especially for survivors. 


\section{5-69 四70-74 $\square$ 75-79 目80-84 8ㅜ 85+ 四Overall}

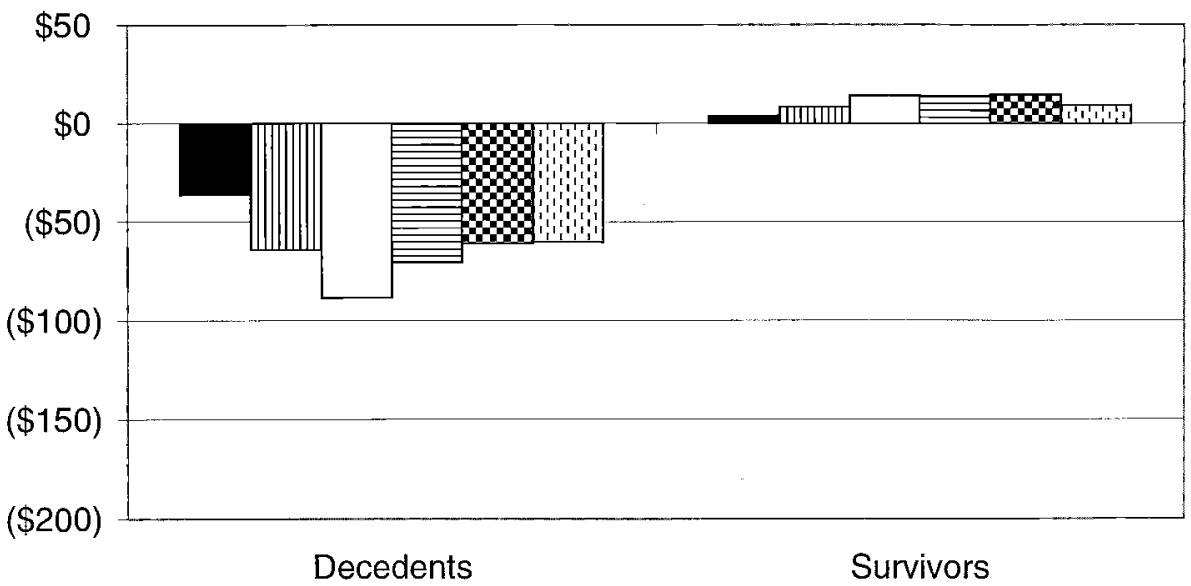

Fig. 6.3 Per-person change in expenditures: 1988 payments $\cdot$ Change in Mortality, 1988-95

Figure 6.3 shows the per-person change in Medicare spending resulting from mortality declines from 1988 to 1995, holding payments and demographics at 1988 levels. This figure isolates the contribution of changes in age-specific mortality rates to spending growth over the period. The left side of the figure (decedents) shows the per capita cost reduction from averting the higher costs of dying. The right side of the figure (survivors) shows the per capita cost increases from the greater number of survivors. Because we are focusing on current-year Medicare costs, we do not show the higher costs of survivors in future years in this figure. The net expenditure impact on current-year costs, the difference between the decedent and survivor effects, depends on both the change in mortality and the difference in expenditures between survivors and decedents in the demographic group. The expenditure impact of mortality rate declines was greatest for the seventy-five to seventy-nine age group (which has intermediate mortality rates and spending differences), resulting in a $\$ 74$ per person decline in payments. The overall decline in per-person payments was $\$ 51$. Thus, mortality improvements did influence spending growth, but the magnitude of the effect was modest.

Figure 6.4 shows that the expenditure impact of mortality-rate declines was larger for males, and more variable across age groups, with an overall decline in per-person payments of $\$ 88$ (including a $\$ 147$ per person decline for the seventy-five to seventy-nine age group). The per capita cost increases from the greater number of male survivors was also higher for the seventy-five to seventy-nine age group, but still small in magnitude. Figure 


\section{5-69 血70-74 $\square 75-79$ 目80-84 8 85+ 田Overall}

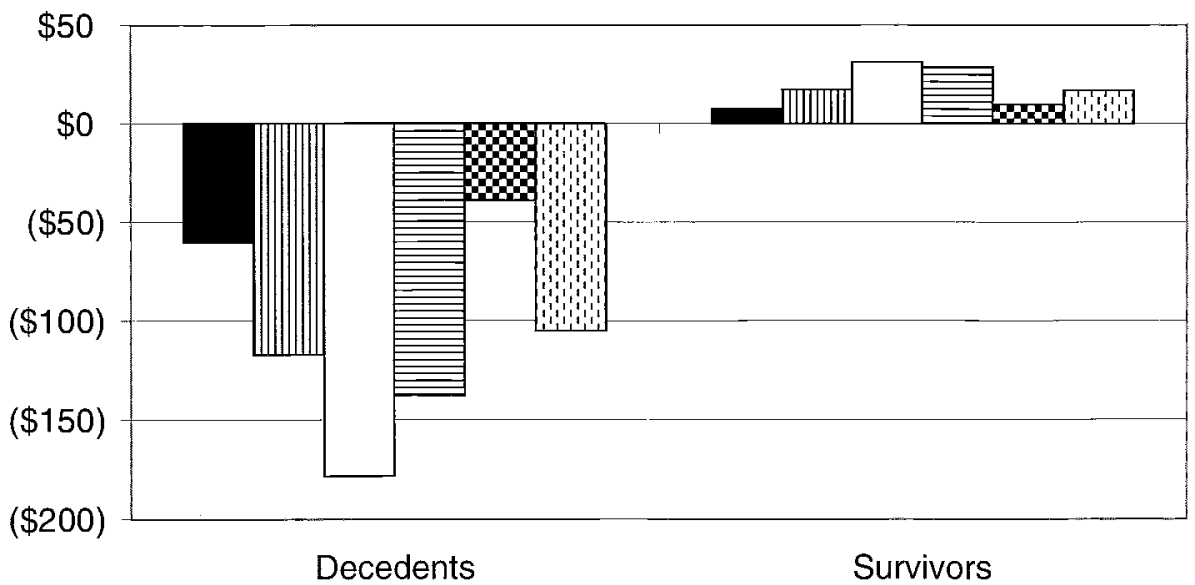

Fig. 6.4 Per-male change in expenditures: 1988 Payments $\cdot$ Change in Mortality, 1988-95

65-69 皿70-74 口75-79 目80-84 885+ 凹Overall

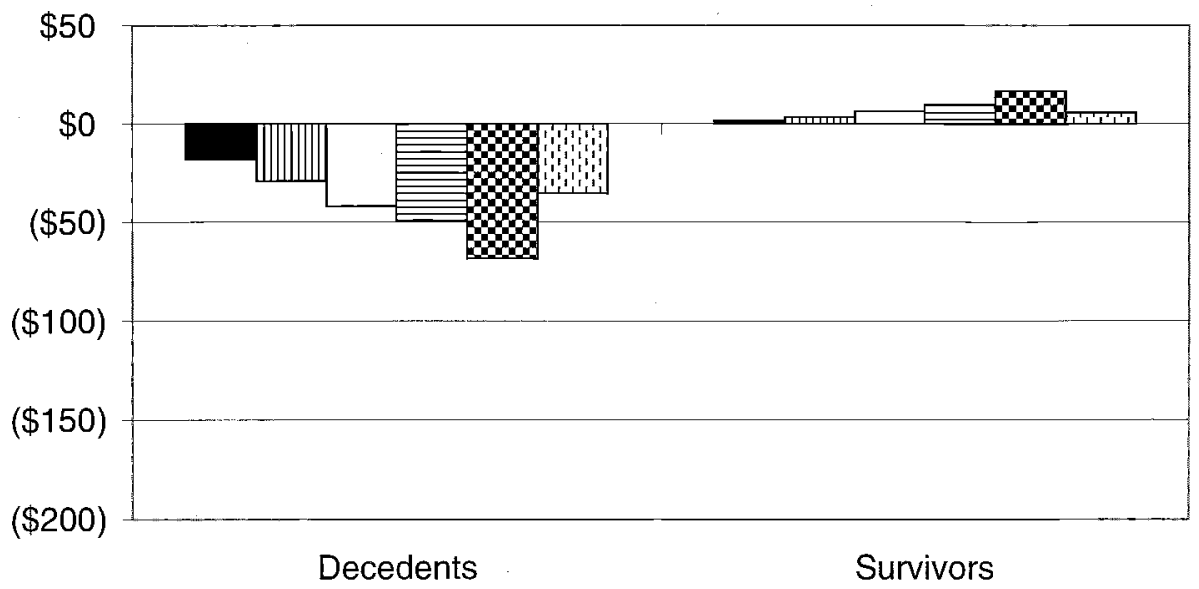

Fig. 6.5 Per-female change in expenditures: 1988 Payments $\cdot$ Change in Mortality, 1988-95

6.5 shows that, for females, the expenditure impact of mortality rate declines was considerably smaller, less than $\$ 30$ per person. In contrast to males, the impact was greatest for the oldest females, those aged eightyfive and up, with a per-person decline in payments of \$52. These differences were primarily the result of a weaker relationship between age and 
65-69 血70-74 口75-79 目80-84 쇼 85+ 田 Overall

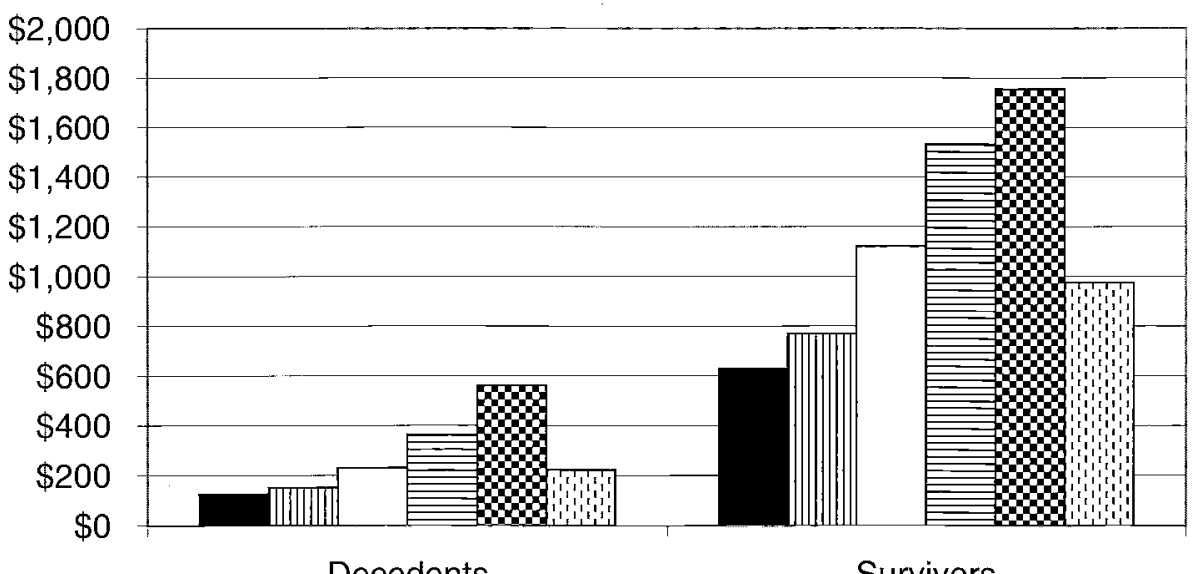

Decedents

Survivors

Fig. 6.6 Per-person change in expenditures: 1988-95 Change in Payments • 1988 Mortality

the difference in expenditures between decedents and survivors than for males; thus, the larger absolute mortality gains at older ages were relatively more important.

Figure 6.6 shows the per-person change in Medicare spending resulting from changes in expenditures per beneficiary, holding age-specific mortality rates (and demographics) at 1988 levels. This figure isolates the contribution to spending growth of changes in expenditures within survival groups. It is obvious from the figure that these changes dwarf the reductions in expenditures from lower mortality over time. Not only does the growth in per capita expenditures due to higher spending on decedents far exceed the savings from reduced mortality, but the effect of spending growth for survivors on per capita expenditures was significantly greater than that for decedents. Even though the absolute spending increases were lower, survivors comprise the bulk of Medicare spending because they comprise the vast majority of Medicare beneficiaries. In contrast to the mortality effects described above, the magnitude of the utilization effect increases with age for both survivors and decedents. Figures 6.7 and 6.8 show that similar patterns hold for both males and females, with a slightly larger utilization effect for females at older ages.

Table 6.1 summarizes the decomposition of expenditure growth described in the preceding figures. The mortality effect is the share of perperson expenditure growth explained by the reduction in age-specific mortality, and the utilization effect is the share explained by the increase in expenditures given survival status. These are both first-order approximations, but as the interaction effect shows, the approximation is close. The 


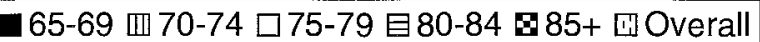

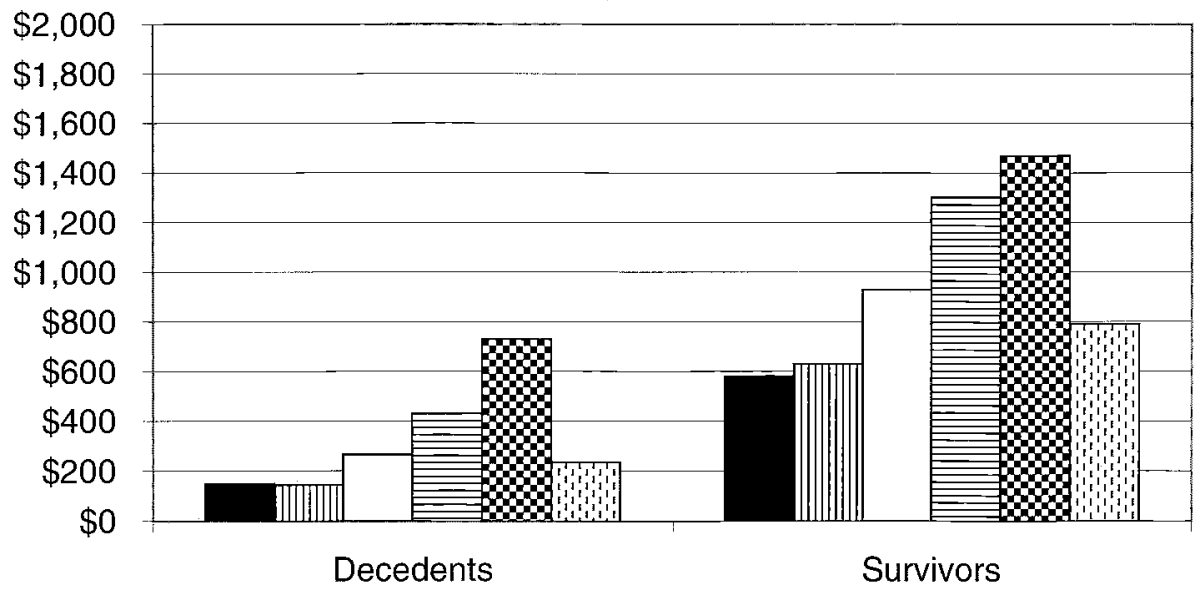

Fig. 6.7 Per-male change in expenditures: 1988-95 Change in Payments • 1988 Mortality

65-69 四70-74 $\square 75-79$ 目80-84 8 85+ 田 Overall

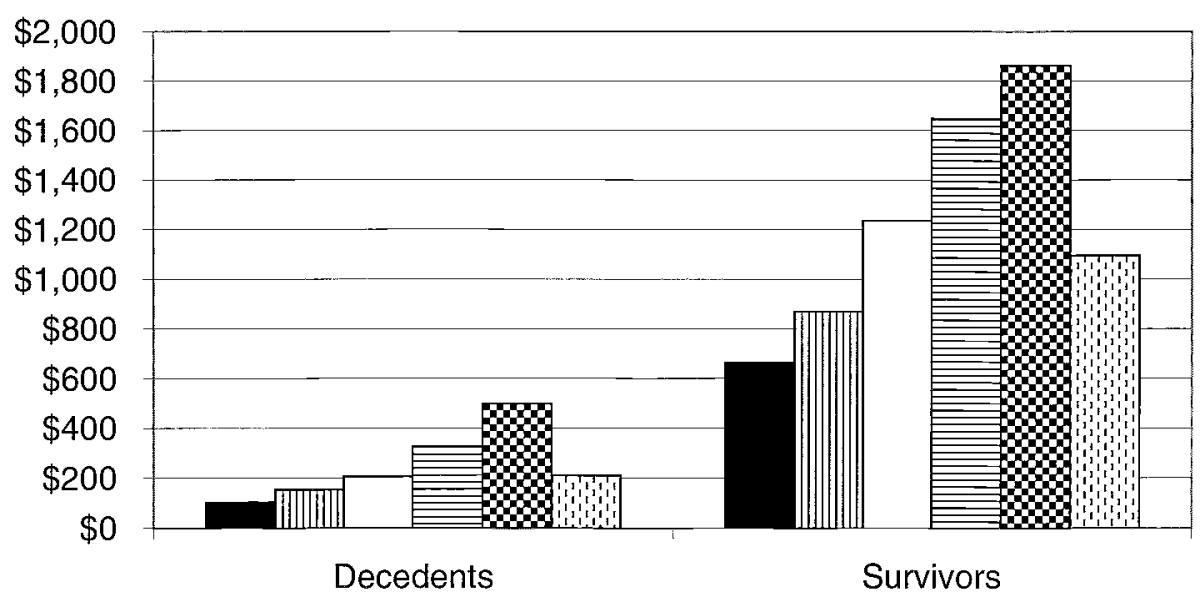

Fig. 6.8 Per-female change in expenditures: 1988-95 Change in Payments • 1988 Mortality

mortality effect is a small contributor to overall expenditure growth: Compared to observed expenditure growth, the analysis suggests that Medicare expenditures per beneficiary would have grown by about 4 percent more over the 1988-95 period if no mortality improvement had occurred. The mortality effect is larger for males than females. For males, Medicare ex- 
Table 6.1

Percent Explained by the Mortality Effect versus the Utilization Effect

\begin{tabular}{|c|c|c|c|c|c|}
\hline $\begin{array}{l}\text { Gender and } \\
\text { Age Groups }\end{array}$ & $\begin{array}{l}\text { Per Person } \\
\quad(\$)\end{array}$ & $\begin{array}{c}\text { Demographic } \\
\text { Effect }(\%)\end{array}$ & $\begin{array}{l}\text { Mortality } \\
\text { Effect (\%) }\end{array}$ & $\begin{array}{l}\text { Utilization } \\
\text { Effect (\%) }\end{array}$ & $\begin{array}{c}\text { Interaction } \\
\text { Effect (\%) }\end{array}$ \\
\hline Overall & 1,135 & 10.2 & -4.5 & 105.5 & -1.0 \\
\hline \multicolumn{6}{|c|}{ Males } \\
\hline Overall & 922 & 10.6 & -9.6 & 111.4 & -1.8 \\
\hline $65-69$ & 665 & 1.5 & -7.9 & 110.2 & -2.2 \\
\hline $70-74$ & 660 & 14.2 & -15.1 & 117.2 & -2.1 \\
\hline $75-79$ & 1,022 & 13.4 & -14.4 & 116.9 & -2.5 \\
\hline $80-84$ & 1,604 & 21.0 & -6.8 & 108.1 & -1.3 \\
\hline $85+$ & 2,163 & 21.2 & -1.4 & 101.7 & -0.3 \\
\hline \multicolumn{6}{|c|}{ Females } \\
\hline Overall & 1,269 & 9.9 & -2.3 & 102.9 & -0.6 \\
\hline $65-69$ & 746 & 0.0 & -2.2 & 102.9 & -0.7 \\
\hline $70-74$ & 990 & 12.4 & -2.6 & 103.3 & -0.7 \\
\hline $75-79$ & 1,397 & 9.8 & -2.5 & 103.2 & -0.6 \\
\hline $80-84$ & 1,924 & 16.8 & -2.1 & 102.6 & -0.6 \\
\hline $85+$ & 2,303 & 22.7 & -2.2 & 102.6 & -0.3 \\
\hline
\end{tabular}

penditures per beneficiary would have grown by about 9.6 percent more if no mortality improvements had occurred. The percentage is even larger for middle-range elderly males (aged seventy to seventy-four and seventyfour to seventy-nine) nearly 15 percent. For females, expenditures per beneficiary would have grown only 2.3 percent more, and that percentage remains the same over all female age groups. This suggests that for one demographic group, namely males aged seventy to seventy-four and seventyfour to seventy-nine, the mortality effect did have some impact on expenditure growth, although the utilization effect was still eight times greater. Overall, the mortality effect had only a modest impact on per-beneficiary expenditure growth because the utilization effect was large in comparison, more than twenty times greater.

Table 6.2 describes the contributing factors to the large utilization effect in more detail. The table shows that utilization increases for survivors accounted for around 73 percent of utilization growth - virtually identical to their share of base-year spending, again indicating that utilization effects are large for survivors as well as decedents. Table 6.2 also shows that nonacute spending for both survivors and decedents accounted for just over half of the utilization effect. This may seem like a relatively small share given the enormous differences in growth rates, but it is a reflection of the fact that nonacute spending represented only a small share of Medicare costs at the beginning of the study period. This is a marked change from the earlier history of Medicare spending growth. For the 1976-88 analysis by Lubitz and Riley, nonacute spending growth likely accounted for virtually all of the utilization effect. Moreover, the importance of nonacute care 
Table 6.2

Contributing Factors to Utilization Effect

\begin{tabular}{lccccc}
\hline & \multicolumn{2}{c}{ Acute-Care Utilization } & & \multicolumn{2}{c}{ Nonacute-Care Utilization } \\
\cline { 2 - 3 } $\begin{array}{l}\text { Gender and } \\
\text { Age Groups }\end{array}$ & $\begin{array}{c}\text { Decedents } \\
(\%)\end{array}$ & $\begin{array}{c}\text { Survivors } \\
(\%)\end{array}$ & & $\begin{array}{c}\text { Decedents } \\
(\%)\end{array}$ & $\begin{array}{c}\text { Survivors } \\
(\%)\end{array}$ \\
\hline Overall & 12.39 & 36.03 & 14.72 & 36.86 \\
& & Males & & \\
Overall & 16.17 & 38.56 & & 16.98 & 28.29 \\
65-69 & 18.68 & 53.12 & & 9.09 & 19.09 \\
$70-74$ & 16.11 & 43.13 & & 13.90 & 26.80 \\
$75-79$ & 16.95 & 38.83 & & 16.76 & 27.51 \\
$80-84$ & 14.60 & 27.84 & & 21.62 & 36.04 \\
$85+$ & 12.16 & 16.52 & & 31.63 & 39.60 \\
& & & & \\
Overall & 10.10 & Females & & & 42.28 \\
$65-69$ & 10.84 & 54.27 & & 13.33 & 27.69 \\
$70-74$ & 11.70 & 42.36 & & 9.79 & 36.12 \\
$75-79$ & 10.15 & 32.41 & 12.58 & 44.81 \\
$80-84$ & 9.56 & 27.99 & 14.25 & 48.21 \\
$85+$ & 8.34 & 16.92 & 21.92 & 52.78 \\
\hline
\end{tabular}

in the utilization effect was highly age and sex dependent: For elderly males, nonacute care accounted for 45 percent of the utilization effect; for sixty-five-to sixty-nine-year-old males, nonacute care accounted for less than one-third of the total utilization effect; for sixty-five-to sixty-nineyear-old females, a little over one-third; and for beneficiaries aged eightyfive and older, it accounted for over two-thirds of the effect. For all ages, nonacute care was a somewhat more important contributor to the utilization effect for females than for males.

\subsection{Discussion}

Our analysis of recent trends in Medicare spending near the end of life has three major conclusions. First, the rate of spending growth was similar for survivors and decedents - actually slightly larger for the oldest female survivors than for other demographic groups, as a result of relatively more rapid growth in spending for nonacute services. Thus, spending growth for survivors continues to account for most of the growth in Medicare costs. This seems to reflect a modest but important long-term trend. For Medicare's first decade, the rate of spending growth was slightly higher for decedents than survivors; and between the late 1970s and late 1980s, the growth rate was similar for the two groups.

Second, in recent years growth in spending for nonacute services has accounted for half of overall spending growth. Thus, spending growth for 
decedents was not primarily the result of increasing heroic, intensive measures near the end of life. In addition, although greater coverage of nonacute alternatives might be expected to affect end-of-life costs disproportionately, growth rates for nonacute services were even greater for older survivors than decedents. Large utilization effects for both acute and nonacute services occurred in both groups.

Third, although improvements in mortality have helped limit Medicare spending growth over time, this effect has been swamped by the much larger increases in expenditures given survival status for decedents and survivors alike. Without the survival improvements, our estimates suggest that total Medicare spending per beneficiary would have grown only 4 percent more than it did. Improvements in mortality were relatively more important in limiting spending growth for males than for females, and for mid-elderly males especially, but still much smaller than the larger increases in expenditures given survival status. Thus, we conclude that increasing utilization for both survivors and decedents has been a far more important determinant of Medicare spending over time than have improvements in mortality. If anything, the slightly more rapid recent growth in spending in some survivor groups-due to the increasing importance of nonacute care-suggests that survival improvements have probably become even more marginal contributors to explaining trends in spending.

This is not to say that the growth in Medicare spending has been wasteful. Life expectancy for an average elderly Medicare beneficiary increased by 4.9 months between 1988 and 1995, at a total cost to Medicare of $\$ 1,135$ - that is, around $\$ 2,780$ per additional life-year. If an additional life-year were valued at only $\$ 25,000$, the increased Medicare spending would be worthwhile if it accounted for only 11 percent of the observed improvement in mortality. Moreover, as we noted above, much of the spending growth occurred in chronic, supportive-care services that would be expected to improve quality of life as well as its length. Thus, although improvements in health have probably offset a miniscule share of the growth in medical spending over the past decade, it does not imply that such spending growth is excessive. However, it does imply that, unless the future is fundamentally different, improving mortality may not have a very noticeable impact on medical spending growth.

\section{References}

Health Care Finance Administration (HCFA). 2000. Data users' reference guide. Baltimore, Md.: HCFA.

Kennedy, Donald. 1994. Health care costs and technologies. The Western Journal of Medicine 161:424-5. 
Lubitz, James, James Beebe, and Colin Baker. 1995. Longevity and medicare expenditures. New England Journal of Medicine 332:999-1003.

Lubitz, James, and Gerald Riley. 1993. Trends in medicare payments in the last year of life. New England Journal of Medicine 338:1092-6.

Pardes, Herbert, Kenneth G. Manton, Eric S. Lander, H. Dennis Tolley, Arthur D. Ullian, and Hans Palmer. 1999. Effects of medical research on health care and the economy. Science 283:36-7.

Piro, Paula, and Theodore Lutins. 1974. Utilization and reimbursements under Medicare for persons who died in 1967 and 1968. Department of Health, Education, and Welfare Publication no. 74-11702.

Singer, Burton, and Kenneth Manton. 1998. The effects of health changes on projections of health service needs for the elderly population of the United States. Proceedings of the National Academy of Sciences 95:15618-22.

Vaupel, James. 1997. The remarkable improvements in survival at older ages. Philosophical Transactions of the Royal Society of London Series B: Biological Sciences 352:1799-1804.

\section{Comment David M. Cutler}

Geppert and McClellan present an interesting analysis of the roles of mortality change and intensity change in explaining the growth of Medicare costs. End-of-life spending is a substantial component of Medicare costs; those in the last year of life use six times more Medicare services than those not in the last year of life. Furthermore, people who die at later ages consume fewer Medicare services at the end of life than those who die at younger ages. The combination of these two factors means that as mortality rates fall and deaths occur at later ages, Medicare spending should fall.

Geppert and McClellan argue that this view is right but quantitatively small. Much more important is the fact that costs have increased for everyone - those near and farther away from death. This "intrinsic cost growth" has driven the Medicare system in the past, they argue, and will continue to do so in the future.

Geppert and McClellan reach a conclusion similar to that of my own work (Cutler and Meara chap. 7 in this volume, and Cutler and Sheiner 1999). In all three papers, technological change is the beast in the system: rapid growth of technology, high Medicare costs; slow growth of technology, lower costs. I am more or less in agreement with all that Geppert and McClellan say.

My one hesitation is that Geppert and McClellan look only at mortality, not at overall health. In addition to living longer, people are healthier. Since healthier people spend less than sicker people, the improvement in health is another form of cost saving. For example, those with five or more

David M. Cutler is professor of economics at Harvard University and a research associate of the National Bureau of Economic Research. 
Forecasts of Medicare Spending

\begin{tabular}{lcccc}
\hline & 1992 & 2010 & 2030 & 2050 \\
\hline Age and sex only & 1.00 & 1.03 & 1.01 & 1.09 \\
$\begin{array}{l}\text { Age, sex, and improved health } \\
\text { Age, sex, improved health, and intrinsic }\end{array}$ & 1.00 & 0.97 & 0.90 & 0.91 \\
$\quad$ cost growth & 1.00 & 1.59 & 3.59 & 6.12 \\
\hline
\end{tabular}

Source: Cutler and Sheiner (1999).

activities of daily living (ADL) impairments (inability to perform basic tasks such as bathing, cleaning, etc.) spend perhaps $\$ 7,000$ per year in Medicare, whereas those with no disability might spend $\$ 1,000$ to $\$ 2,000$. As disability rates fall, average spending will fall as well.

To evaluate the magnitude of this, Manton, Corder, and Stallard (1997) show that disability rates among the elderly are falling by 1 to 1.5 percent per year. Over the decade which Geppert and McClellan examine this would reduce average disability rates by 10 to 15 percent. The implied reduction in spending is about 5 to 10 percent. This is of moderate size.

Indeed, looking forward, improvements in health may play a more important role in forecasting medical costs than they did in the past. Table 6C.1 shows forecasts of medical spending on the elderly between 1992 and 2050, taken from Cutler and Sheiner (1999). The first row uses standard projections for Medicare projections. Medicare costs vary by age and sex, but not by health status. For clarity, age- and sex-specific costs are assumed to be constant over time, so only changes in the age and sex distribution of the population affects spending. The increased share of the older population is projected to raise spending by 9 percent over the next halfcentury.

The next row shows the effect of improved health-both reduced morbidity and reduced mortality. Compared to the projection without accounting for better health, the difference in 2050 is 18 percent (from a 9 percent increase to a 9 percent decrease). The change is substantial.

The third row shows the impact of intrinsic cost growth at the same rate relative to gross domestic product as the past half-century. If costs continue to rise at this rate, per-person spending will increase by 500 percent in the next half-century. Clearly, these intrinsic increases dominate the Medicare future. Demographics are much less important.

However, the link between demographics and intrinsic growth may be more subtle. On the one hand, health changes may be driven by increased spending, so that spending increases in the future might have even larger effects on the health of the elderly. On the other hand, demographic change may affect the rate of intrinsic cost growth. As people become healthier, will spending growth rise, as more-healthy people receive intensive treatments? Or will spending growth fall as we learn how to prevent disease 
more cheaply? These are the important questions that research needs to address. Geppert and McClellan's paper, along with other work on this topic, has provided an important start.

\section{References}

Cutler, David, and Louise Sheiner. 1999. Demographics and Medical Care Spending: Standard and Non-Standard Effects. In Demographics and Fiscal Policy, eds., A. Auerbach and R. Lee, Cambridge: Cambridge University Press.

Manton, Kenneth, Larry Corder, and Eric Stallard. 1997. Chronic Disability Trends in Elderly United States Populations: 1982-1994. Proceedings of the National Academy of Sciences, 94:2593-2598. 